\title{
Frederico Nietzsche*
}

\author{
João Ribeiro**
}

\begin{abstract}
Resumo: Artigo publicado em 1904, no Almanaque Garnier. Nele, o autor trata de vários temas da filosofia nietzschiana sem perder de vista o contexto cultural brasileiro. $\mathrm{O}$ artigo, segundo o autor, foi motivado pelo falecimento da mãe de Nietzsche. É ainda um dos primeiros textos escritos sobre a filosofia de Nietzsche no Brasil.
\end{abstract}

Palavras-chave: Nietzsche - pró-homem - mulher - cristianismo

Há já alguns anos, negra loucura obscureceu o gênio de Nietzsche, do homem sonhador da humanidade futura e do "homem solitário e forte como a águia", o Adlermensch, que virá, um dia, substituir o homem atual e ridículo, o homem-macaco, Affenmensch. O filósofo que sonhara o tipo do pró-homem (Übermensch) onipotente, fora da moral e das convecções, realizando, na plenitude de toda a liberdade, toda sua força individual, paixões, instintos ou talentos, ei-lo caído em imbecilidade lobrega e terrível, perdida a razão e a palavra e o senso comum. Todos os amigos, senão um, lhe fugiram.

\footnotetext{
* Artigo publicado no Almanaque Brasileiro Garnier (A.B.G.). Rio de Janeiro, 1904, p. 247250. Reeditado no livro O Fabordão (Crônica de vário assunto), publicado em 1910. Tudo indica que a última edição de $O$ Fabordão é de 1967, com Prefácio de Augusto Meyer, Revisão crítica e notas de Aurélio Buarque de Hollanda. Livraria São José LTDA, Rio de Janeiro. João Ribeiro sugere que a data de composição do texto é 1896. Informa ao leitor que foi composto em Berlim, motivado pela morte da mãe do filósofo. Contudo, considerando que a mãe de Nietzsche faleceu em abril de 1897, acreditamos que a composição do ensaio de João Ribeiro aqui transcrito deve remontar mais precisamente ao ano de 1897.** Tristão de Alencar Araripe Júnior (1848-1911). Crítico, cronista e membro da Academia Brasileira de Letras. ** João Batista Ribeiro de Andrade Fernandes (1860-1934). Filólogo, historiador, jornalista, poeta, folclorista, ensaísta, crítico literário.
} 
Ribeiro, J.

Alguém apenas, em desveladas noites, acompanha esse fúnebre epílogo de vida, no canto de um hospício, e era a sua pobre mãe, carinhosa e inesgotável de ternura. Esse último raio ainda agora lhe sonegara as inclemências da sorte. A mãe de Nietzsche morreu. A única palavra que o louco balbuciava, mamma, único e último vestígio do entendimento, já não aplica a coisa alguma.

Não é meu intento aqui traçar uma exposição da filosofia de Nietzsche. Outros já o fizeram com paciente e castigado lavor, mas todos também com demasias e exageros. Difícil era achar a unidade caos aparente. Porque em verdade foi Frederico Nietzsche um grande estranhável inimigo dos sistemas. Ele queria a decomposição de tudo; e a seu grado, o mundo voltaria a ser todo átomos e partículas como o sonhará Epicuro, antes do clinamen fatal que gerou o turbilhão da vida. Sistema? Não tinha essa preocupação. É muito difícil extrair dos seus livros uma intuição geral do mundo, ou uma sintaxe do universo que ele queria sem gravitações e sem obediências. A sua natureza era essencialmente fragmentária e libérrima.

Pode dizer-se que ele pensava como escrevia: em pequenos cadernos, hábito que lhe tornava inúteis a mesa e a escrivaninha, e era mais propício ao flagrante dos seus lampejos. Ensaios e aforismos. Não é difícil apanhá-la em contradição, como o faria uma crítica estreita em mesquinha; o mais certo seria, e é, apanhá-lo em progresso inconstância.

Tomava o seu espírito todas as atitudes; era filólogo, erudito, era literato e artista genial da palavra, poeta e filósofo.

Pode-se de algum modo ligá-lo a Schopenhauer, mas nem essa comunhão obriga-o, e ei-lo, em breve, um inovador idealista. Schopenhauer verificava a miséria animal e não achava outro remédio ou conselho senão no Nirvana. Ao contrário, Nietzsche sonhava evolução nova, a do sobre-homem, mas já não pelo processo darwínico ou goethiano a fome e o amor, mas por uma seleção nova, guerreira sem dúvida, e, todavia intelectual. Para Nietzsche a luta pela vida não se faria mais pelo pedaço mesquinho de pão, mas ao contrário, pela vitória do supérfluo, da riqueza, da arte e do gênio.

138 | Cad. Nietzsche, São Paulo, v.I n.35, p. 137-144, 2014. 
Os vencedores hão de serem, como heróis da Renascença, os Médices magníficos e os Bórgias afrontadores da vida. "Poder cada vez mais" eis o verdadeiro lema. Assim, o grande herói moderno era Napoleão, o inimigo da fraternidade revolucionaria de 89, o renovador da sociedade conquistadora antiga.

O futuro será, de alguma maneira, uma obra napoleônica.

Esse caráter da vida futura exclui necessariamente a moral de hoje. Sobretudo, o grande obstáculo, dizia Nietzsche, é o Cristianismo, religião dos humildes e dos fracos, religião dos pobres e vagabundos; e as suas consequências diretas ou indiretas: o socialismo, que a vitória das massas proletárias; a democracia, que é a vitória das massas burguesas... Enfim, o rebanho contra o pastor, o grei contra o chefe.

Nenhuma vitória de multidão. A multidão será no futuro imoral. O caráter do futuro é o triunfo napoleônico, isto é, do indivíduo que, como Bonaparte, objetiva e realiza todas as suas forças, semeia-as, fá-las florir e frutificar, sem embargar de etiquetas, regras, revoltadas, prejuízos e costumes. Homens, como Bórgia, Napoleão, são os precursores do pró-homem, do homem-águia, vencedor do homem-macaco. E a fantasia intrépida e diabólica do filósofo tira todas as conclusões desse extremo individualismo.

Nietzsche queria, pois, a inversão de todos os valores, como ele dizia. Até agora na cristandade a tudo quando existe de forte se afetou o sinal negativo; é mister inverter. Guerra aos fracos, guerra aos pobres, guerra aos doentes; glória à vocação de rei, glórias a quem pode e maiores a quem pode mais.

Mas, como disse, não é intento meu nem tenho no momento os elementos de perspectiva indispensáveis para dar um escorço sequer de toda a obra de Nietzsche, que, embora fragmentária, é, todavia volumosa e extraordinária.

Aqui neste âmbito da vida alemã em que momentaneamente me acho os entusiasmos, por ardentes e numerosos, sufocam.

$\mathrm{O}$ fato de haver morrido a pobre mãe de Nietzsche, induz-me a conversar com os leitores sobre o que Nietzsche pensava acerca 
Ribeiro, J.

da "Mulher", tema sempre debatido dos psicologistas, máximos e mínimos, e que não é raro encontrar desenvolvimento, assim em um auditorium alemão como em uma modesta sociedade literária da Cidade Nova.

Seja como for, parece que a única coisa apurada a respeito da mulher é essa banalidade profunda, a saber: que ela é um enigma. Todos os matizes são de si mesmos sutis, difíceis e às vezes impenetráveis, e é por isso que, segundo Stirner, o homem conhece hoje melhor o cavalo do que a mulher.

A diferença do sexo introduz no ser feminino uma série de novos desarranjos sanguíneos, que pela nossa impossibilidade de sentir estamos impossibilitados de compreender. Um hermafrodita perfeito que tenha consigo a função da perpetuidade da espécie pudera dizer ex-cathedra; mas desde que o homem está lascado em dois, agora aí ficam duas partículas incomensuráveis e ininteligíveis.

O feminino na animalidade não é só o caráter de alguns órgãos, mas vai até cada uma das células em todos os seres; a soma de caracteres celulares é que pode decidir do sexo, porque todos os seres, em regra, são hermafroditos.

Cuidado com a equação pessoal!

Para Nietzsche, que prega o egoísmo, o amor é a suprema fraude.

É sabido que o filósofo se comprazia melhor na companhia das mulheres que na dos homens, que ele evitava.

Nietzsche acreditava que no amor havia o autoengano (e não é minha essa hibrida expressão) e o engano reciproco. A ideia de igualar dois entes, transfundir-se um no outro, não tem outro impulso que o medo. E é isso o que faz de todo o amor, por mais sublime que seja uma questão de comédia (Schauspielerei). O essencial na paixão é a sede egoísta de posse e tão absolutamente egoística, que o amoroso verdadeiro e extremado pensa sempre em matar a amante, isto é, em acessar cessar a possibilidade de qualquer alienação da sua posse.

Daí essa comédia consciente ou inconsciente de sacrifícios, de 
dedicação e até de indignidade. No amor há parcelas femininas de ambas as partes, no homem e na mulher, que se medem e se cotejam nos obscuros equilíbrios da natureza.

Mas esse é o amor do homem ínfimo, isto é, do homem atual. No futuro os impulsos sexuais cederão a uma serena amizade, e o casamento será como diz o filósofo, "um longo diálogo. Não se pense, porém, que haja uma grande santidade nessa doutrina. Ao contrário, o pró-homem é essencialmente livre e essencialmente volúvel; para ele nada há definitivo, nem sequer duradouro; não há laços nem liames que o tolham. Não há posses exclusivas, nem há subordinações senão ocasionais. 0 pró-homem não tem hábitos, porque os "hábitos são fios tenuíssimos que se transformam em cordas, que nos fazem prisioneiros e nos obrigam a viver do próprio sangue". Tudo isso se exclui no reino do homem-águia, solitário e forte.

Não é isso um mero eufemismo? E por que não instituir logo como no antigo Oriente o hetairismo sagrado? Se sua função é a da espécie, por que a roubando à espécie e à tribo entregá-la a um indivíduo sempre pouco para substituir a horda?

A impossibilidade maior contra a intuição do caráter feminil resulta no presente de que o homem espiritualizou a mulher, aniquilou-a quase, tornou-a volátil, ideal e pouco terrestre, conservando-a, entretanto, barbara e quase um ente inferior. Entrando na família, esterilizou-se. Arrancou-se lhe o ovário aos ventos carregados de pólen, para o fecundarem no seco e estúpido laboratório artificial das alcovas monogâmicas. Nietzsche disse uma vez: - O homem, de uma costela de seu Deus, fez a mulher.

Esse aforismo paradoxal é mais significativo do que parece à primeira vista.

O homem fez da mulher alguma coisa de divino, fê-la quase uma religião, nos tempos da gaia cavalaria e em todos os tempos da poesia, na arte antiga e na moderna, outrora e hoje. O ateísmo inverterá todos esses valores, com a derrocada de todas as divinizações e apoteoses antigas. 
Ribeiro, J.

Mas e suma a filosofia de Nietzsche não dá à mulher senão um caráter antipático, ainda que exalte os fulgores e as radiações da sua beleza.

Para o filósofo, tudo de quando é capaz a mulher ressente-se da sua função máxima e axial.

Todos os atos da mulher participam de sua natureza hetairiana: ama por quarenta anos, omnia vivit, e se parece sucumbir tem a aptidão de chorar e desfalecer, isto é, de tornar dolorosas e rápidas as vitorias do homem.

O homem julga-se um fim, mas não é para ela senão um meio, e instrumento da maternidade, embora ela viva em completa subordinação doméstica e social. Mas a honestidade dela destruiu-a depois de fazê-la escrava. A monogamia, como outrora o pelourinho, serviu um momento à paz pública e foi o alicerce de uma civilização. Foi um erro que, como o de Ptolomeu, por alguns séculos equilibrou o universo.

Em outro lugar, na Gaia Ciência, define o filósofo a diferença entre o amor da mulher, que é inteira renúncia e abdicação de si própria, e o amor do homem, que absorve e faz da mulher uma mera parcela na soma dos seus instintos de proprietário. A conclusão evidente é que a fidelidade é essencial na mulher, mas é virtude fútil e duvidosa no homem, senhor ilimitado e que talvez ainda mais se robusteça com as parcelas conquistadas.

Os pensamentos de Zaratustra acerca da mulher acham formulas schopenhauerianas e realmente brutais, como esta:

"Alles am Weibe ist ein Rätsel, und Alles am Weibe hat Eine Lösung: sie heisst Schwangerschaft." Zarath. 95.

Daí o ódio da mulher pelo amante imperfeito. É o ódio, diz ele, do ferro que diria ao magneto: odeio-te porque me atrais, mas não tens força bastante para atrair-me até converter-me em ti.

Nestas e em outras teorias tais há o excesso tendencioso da fisiologia hoje demasiado entremetida na ciência do homem. A civilização de nada valeria se não houvesse criado outros estímulos menos bestiais. 
Um dos passos mais curiosos da opinião do filósofo e do poeta sobre as qualidades feminis é a sua teoria da beleza. Considera a beleza como expressão estática da forma humana. Os órgãos de agressão e defesa no homem reclamam violência de movimento, na mulher apenas os leves gestos, a quase quietude. Por exemplo, o olhar do homem está habituado a produzir o medo e os sinais da energia e do mando; o da mulher é veludoso e educa-se em atraí-lo. A violência e o exercício no homem criam as asperezas de superfície do corpo pelo desenvolvimento de ossos e músculos. A maternidade ou a sua predestinação avoluma as formas no ventre, nos seios e nos membros inferiores.

A visão dessas formas, sem claro-escuro, não tem angulosidade, e é suave como a do céu a de um lago, e gerou toda a estética; porque o que nós chamamos de belo é aquilo que pelas curvas ou por outras associações remotas nos lembram formas e estímulos genéticos, por menos que o pareçam. A beleza por mais abstrata que seja é sempre erótica; todas as coisas belas são próxima ou remotamente afrodisíacas.

Essas diferenças não seriam bastante para explicar a beleza feminil que se origina do costume: o tipo feminino é o tipo estável, o mesmo da antiguidade e de hoje, o tipo que guarda e mantém a forma da espécie; o tipo masculino, ao contrário, é vário e transitório, diverso hoje do de ondem, ligado aos exercícios profissionais, sem tradição plástica assentada.

Mas este é apenas um aspecto da filosofia desse louco genial e um episódio da sua obra que é toda voltada contra a solidariedade humana, e contra o cristianismo.

Afinal, o cristianismo (que foi o grande mal da história humana para o filósofo) era coisa inevitável.

Pouco importa o nome e os pormenores da legenda cristã, a verdade mais profunda é que o cristianismo é uma grande fase da espécie que se abriu quando ela atingiu a madureza heleno-romana. $\mathrm{O}$ homem greco-romano estava preparado para ser incoercivelmente cristão. Ao ideal da força e da expansão egoísta de todos 
Ribeiro, J.

os instintos, degenerados e mórbidos como a própria sociedade, sucedia tranquilamente a reação humanitária e misericordiosa da justiça e da compaixão pelos humildes e vencidos e escravos que eram unanimidade do mundo.

$\mathrm{O}$ cristianismo não foi apenas a vitória dos pusilânimes e da multidão, foi a própria confissão de incapacidade dos triunfadores do gentilismo, combalido pelos mesmos miasmas da vitória. Os cristãos eram os abstêmios contra os ébrios, os castos contra os tísicos da sensualidade, equilíbrio da pobreza contra as arritmias mórbidas da plutocracia antiga.

O cristianismo era, pois, como se anunciava, a redenção; não a redenção dos judeus e dos místicos, mas a que o instinto mais profundo da espécie acordava no homem como prêmio da vida na aniquilação da antiga sociedade anarquizada e agonizante.

Neste sentido, quase por assim dizer sob essa luz antropológica, todos nós, os mesmos ateus, somos cristãos: isto é, continuamos a ter sede de justiça e trabalhamos, com amor e fé e esperança, pelo ideal da igualdade.

Pouco importa se desparece a legenda poética do Cristo e com ela todos os dogmas das religiões cristas; ainda menos importa que outras doutrinas se levantem para substituir o lábaro do proximismo e da caridade. O grande e o maior significado é que a bandeira da justiça no Gólgota ou em qualquer acrópole do Ocidente será ainda por muitos séculos o grande símbolo da civilização.

Berlim, 1896.

\begin{abstract}
Article published in 1904, in the Almanaque Garnier. In this article, the author deals with various themes of Nietzsche's philosophy without losing sight of the Brazilian cultural context. The article, according to the author, was motivated by the death of the mother of Nietzsche. It is also one of the first texts written about Nietzsche's philosophy in Brazil.

Keywords: Nietzsche - pro-man - woman - Christianity
\end{abstract}

